\title{
ANTI-METHICILLIN RESISTANT STAPHYLOCOCCUS AUREUS POTENTIAL OF PHYTOCHEMICALS IN TERMINALIA CATAPPA AND THEIR PROPOSED IN SILICO MECHANISM OF ACTION
}

\author{
LOKESH RAVI ${ }^{1}$, DIVYA JINDAM ${ }^{2}$, SUGANYA KUMARESAN ${ }^{2}$, VENKATESH SELVARAJ $^{3}$, JAYARAMA REDDY ${ }^{1 *}$ \\ ${ }^{1}$ Department of Botany, St. Joseph's College, Bengaluru, Karnataka, India. ${ }^{2}$ SciWris: Life Sciences, Vellore, Tamil Nadu, India. ${ }^{3}$ Department \\ of Marine Biotechnology, National Institute of Ocean Technology, Chennai, Tamil Nadu, India. Email: drjayaramreddy@sjc.ac.in
}

Received: 26 June 2019, Revised and Accepted: 08 August 2019

\section{ABSTRACT}

Objective: The objective of this study was to investigate the antibacterial potential of leaves of this Terminalia catappa and identify the mechanism of action for those phytochemicals present in this leaves.

Methods: Phytochemicals were extracted using maceration and the extracts were analyzed using gas chromatography-mass spectrometry (GC-MS) to identify the chemical structure. Antibacterial potential was evaluated using agar well diffusion. The phytochemicals were subjected to in silico protein-ligand docking study to identify the mechanism of action.

Results: In vitro antibacterial study demonstrated that the ethanol extract of the leaves has significant antibacterial activity against Staphylococcus aureus (SA) and methicillin-resistant SA (MRSA) with a zone of inhibition of $16 \mathrm{~mm}$ and $18 \mathrm{~mm}$, respectively, at a concentration of $2 \mathrm{mg} / \mathrm{ml}$. The chloroform and hexane extracts of the leaves did not demonstrate any significant activity. Based on GC-MS analysis and literature review, 12 phytochemicals were identified to be present in the ethanol extract of the T. catappa leaves. These molecules were subjected to in silico protein-ligand docking study against common drug target proteins of SA and MRSA. Among the studied ligands, granatin A demonstrated the highest significance to inhibit topoisomerase IV with a binding energy of $-11.3 \mathrm{kcal} / \mathrm{mol}$ and produced 7 hydrogen bonds, followed by punicalin with $-10.7 \mathrm{kcal} / \mathrm{mol}$ binding energy toward penicillin-binding protein $2 \mathrm{a}$ with 6 hydrogen bonds.

Conclusion: Phytochemicals of T. catappa demonstrates significant drug ability potential against drug-resistant MRSA pathogen and demands further investigation on their individual activity and mechanism.

Keywords: Terminalia catappa, Staphylococcus aureus, Antibacterial activity, Protein-ligand docking, Gas chromatography-mass spectrometry.

(C) 2019 The Authors. Published by Innovare Academic Sciences Pvt Ltd. This is an open access article under the CC BY license (http://creativecommons. org/licenses/by/4. 0/) DOI: http://dx.doi.org/10.22159/ajpcr.2019.v12i10.34705

\section{INTRODUCTION}

The folk and traditional medicine practices are based on the properties and uses of plants and its extracts and are recognized as a great potential for the development of new medicines. Plants have inherent potential to synthesize chemical compounds that are useful and aid to uphold themselves against attack from extensive predators such as fungi, insects, and herbivorous mammals. Since decades, humans have been using spices and herbs in their day-t- day lives, which possess many medicinal compounds [1]. The most cost-effective and rapid method for researchers toward exploring the plants' bioactivity potential is reported to be in vitro antibacterial activity assay [2]. Since decades, many researches are being reported on antiviral, antifungal, antimolluscal, antibacterial, anthelmintic, and anti-inflammatory activities of several medicinal, food, and commercial plants [3]. Considering the enormous number of medicinal and medicinally valuable plants present in India, it is surprising that there are no market available antibiotics that are derived from plants. The present study was carried with an objective to assess the antibacterial potential of Terminalia catappa.

T. catappa, commonly known as tropical almond, is one of the large, spearing tropical trees, distributed throughout the warmer parts of Indian and other tropical regions. Various parts of T. catappa such as leaves, fruits, and seeds are studied for multiple bioactivities, since they contain diverse variety of compounds that process many medical benefits. Research on medicinal uses of T. catappa has been reported by several researchers over decades. Leaves and fruits of T. catappa are reported to contain bioactive tannins that astringent in nature [4]. T. catappa leaves and bark extracts are reported to possess anticancer [5], antioxidant [5], antigenotoxic [6], anti-HIV reverse transcriptase [7], anti-inflammatory [8], aphrodisiac [9], hepatoprotective[10], anticlastogenic[11], andantihepatitisactivities [6]. The ethanol extract of T. catappa leaves is reported to inhibit osmotically induced human erythrocyte hemolysis in a dose-dependent manner. Phytochemical molecules "punicalagin" and "punicalin" obtained from extracts of the leaves are reported beneficial for treating dermatitis and hepatitis, since they possess antioxidative activity. T. catappa leaves also function as a vermifuge, and also, the leaves along with mixture of kernel oil are reported to be useful in leprosy treatment [12]. The raw leaf juice is used as ingestion for cough [13]. The leaves are also reported to be beneficial in treating, indigestion, jaundice [13], and bronchial asthma [14] and to cure headaches and colic in babies [12]. Leaves, fruit, and bark are also used to treat yaws [13].

The bark of the plant is useful for bilious fever, thrush, diarrhea, sores, and abscesses $[12,13]$. The bark is also used for treating diabetes and stomach ache [13]. On the other hand, the fruit of this plant researched to possess cyanidin-3-glucoside and corilagin that are said to be topoisomerase I and II inhibitors and also xanthine oxidase inhibitor [15,16], gallic acid [17], ellagic acid [7], anti-asthmatic compound [17], and pentosans. The seed kernel consumption is reported to be useful for the treatment of sexual dysfunctions in men.

Despite the multiple reports of valuable medicinal properties of this commonly available plant, there are no significant publications in the recent decades and are being neglected as a potential source of antibiotic. In this current study, the antibacterial potential of T. catappa leaves is analyzed by in vitro examination against a common pathogen Staphylococcus aureus (SA) and methicillin-resistant SA (MRSA) a 
drug-resistant bacterial pathogen that is a common threat to Indian population. The list of identified compounds that are present in the extract is then analyzed using protein-ligand in silico docking studies, to predict the possible mechanism of action.

\section{METHODS}

\section{Plant extraction}

Shade-dried leaves of T. catappa were mixed with 1:10 ratio of different solvents (EtOH, chloroform, and hexane) and were extracted by maceration for $24 \mathrm{~h}$ at room temperature. The mixture was then filtered and the filtrate was concentrated in rotary vacuum evaporator. The concentrated crude extract was dissolved in dimethyl sulfoxide at a concentration of $10 \mathrm{mg} / \mathrm{ml}$ for biological studies [18].

\section{Agar well diffusion}

The bacterial cultures were freshly prepared before antibiotic susceptibility test using agar well diffusion method assay. The bacterial cultures used were SA (MTCC 6) and clinical MRSA isolate. The isolates were inoculated as a lawn culture on the freshly prepared MuellerHinton agar plates. Wells were punched onto these Mueller-Hinton agar plates using well borers. A total of $200 \mu \mathrm{l}$ of test sample was loaded into each well, with a concentration of $10 \mathrm{mg} /$ well. The plates were incubated at $37^{\circ} \mathrm{C}$ overnight, and diameter of the zone of inhibition was measured [19-21].

\section{Gas chromatography-mass spectrometry (GC-MS)}

The ethanol extract of T. catappa leaves was subjected to GC-MS analysis, at Vellore Institute of Technology University. The sample was also evaluated for area percentage analysis [22-24].

\section{Protein-ligand docking}

The three-dimensional (3D) structure of the protein molecules penicillin-binding protein 2a (PBP2a), topoisomerase IV, dihydropteroate synthase (DHPS), and dihydroorotate dehydrogenase was retrieved from RCSB website www.rcsb.org. The protein molecules were cleaned, by removing all non-amino acid derivatives from the PDB file. The PDB ID of the protein is topoisomerase IV - 2INR, PBP2a - 3ZG5, dihydrofolate reductase (DHFR) - 4FGG, and DHPS - 1AD1. The ligand molecules were downloaded from the PubChem website with the respective ID. Protein-ligand docking was performed using AutoDock Vina. The results of the docking study were visualized using LigPlot-Plus and Pummel tools to study the two-dimensional and 3D interactions, respectively [25].

\section{RESULTS}

\section{Antibacterial potential of $T$. catappa}

Among the 3 studied extracts of T. catappa leaves (ethanol, chloroform, and hexane), the ethanol extract demonstrated significant antibacterial activity against both SA and MRSA, with a zone of inhibition of $16 \mathrm{~mm}$ and $18 \mathrm{~mm}$ at $2 \mathrm{mg} /$ well concentration, respectively. The agar well diffusion method antibacterial activity results are shown in Fig. 1. The results show that the ethanol extract possesses significant antibacterial activity against both the drug-sensitive and drug-resistant SA. The extract demonstrated a slight increase in the activity toward MRSA, suggesting its specificity toward to the drug-resistant pathogen.

\section{GC-MS analysis}

The ethanol extract of T. catappa leaves was subjected to GC-MS analysis to identify its phytochemical constituents. Area\% analysis was done to identify the percentage contribution of individual compounds in the crude extract. The chromatogram image of GC-MS along with the table for area\% analysis is shown in Fig. 2.

\section{Phytochemical constituents}

Based on the mass spectrum data search in the NIST library from GC-MS and based on the literature reports, the following 12 phytochemical molecules were identified to be present in the ethanol extract T. catappa leaves. The compounds are tabulated in Table 1.
Protein-ligand docking study

The identified phytochemicals present in the ethanol extract of T. catappa leaves are subjected to protein-ligand docking study, to predict the mechanism of action of the observed activity. The results of the docking analysis are tabulated in Table 2. A total of 28 dockings were performed, i.e. 12 ligands with 4 proteins. Among the studied drug targets, significant interaction between protein and ligand were observed with topoisomerase IV and PBP2a proteins.

Topoisomerase IV protein is a key enzyme in the DNA replication, playing a key role in the unwinding of DNA. Inhibition of topoisomerase would produce a bacteriostatic effect, by preventing bacterial cell multiplication. The results of this analysis show that granatin A and terflavin A ligands present in the leaf extract shows the highest significance in inhibiting topoisomerase IV, with a free binding energy of $-11.3 \mathrm{kcal} / \mathrm{mol}$ and $-11.2 \mathrm{kcal} / \mathrm{mol}$, respectively. Granatin A demonstrated a strong affinity toward the protein, with formation of 7 hydrogen bonds (Ser-108, Lys-266, Ile-109, Thr-216, Pro-215, and Arg294 ) along with 9 hydrophobic interactions. The molecular interactions between granatin A and topoisomerase IV are graphically represented in Fig. 3.

PBP2a is a cell wall biosynthesis protein that plays a key role in the drug resistance of $\mathrm{SA}$ and characteristic feature of identification of MRSA. PBP2a protein is a low-affinity protein that has poor binding potential with beta-lactam antibiotics. Inhibition of PBP2a would result in bactericidal effect by disruption of the bacterial cell wall. The results of this analysis show that punicalin and terflavin A molecules present in the T. catappa leaves shows significant binding affinity toward inhibition of PBP2a, with a binding energy of $-10.7 \mathrm{kcal} / \mathrm{mol}$ and $-10.4 \mathrm{kcal} / \mathrm{mol}$, respectively. Punicalin produced a strong protein-ligand binding, with 6 hydrogen bonds (Tyr-196, Lys-148, Thr-238, Ser-149, His-293, and Met-372) along with 22 hydrophobic interactions with the residues in the binding pocket. The interactions between punicalin and PBP2a are graphically represented in Fig. 4.

DHPS is a protein involved in the biosynthesis of folic acid. Inhibition of this enzyme would result in a bacteriostatic effect as it would reduce the metabolism of the bacterial cells and prevent further growth/ multiplication of the bacterial cells. The results of this docking study showed that the ligand mupirocin showed significance to inhibit DHPS enzyme with a free binding energy of $-10.2 \mathrm{kcal} / \mathrm{mol}$.

The protein-ligand docking study suggests that the phytochemical molecules present in the leaves of T. catappa have significant potential to inhibit key metabolic enzymes of the Gram-positive bacterium, correlating to the observed in-vitro antibacterial activity.

\section{DISCUSSION AND CONCLUSION}

In silico prediction of the bioactivity of target molecules and prediction of mechanism of action of observed activity is a popular approach that is attracting spotlight in the recent years toward acceleration

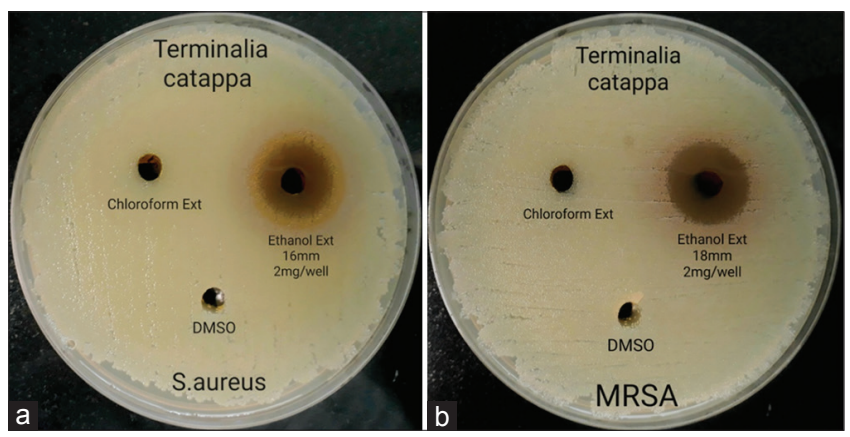

Fig. 1: (a and b) Antibacterial potential of Terminalia catappa against Staphylococcus aureus (SA) and methicillin-resistant SA 


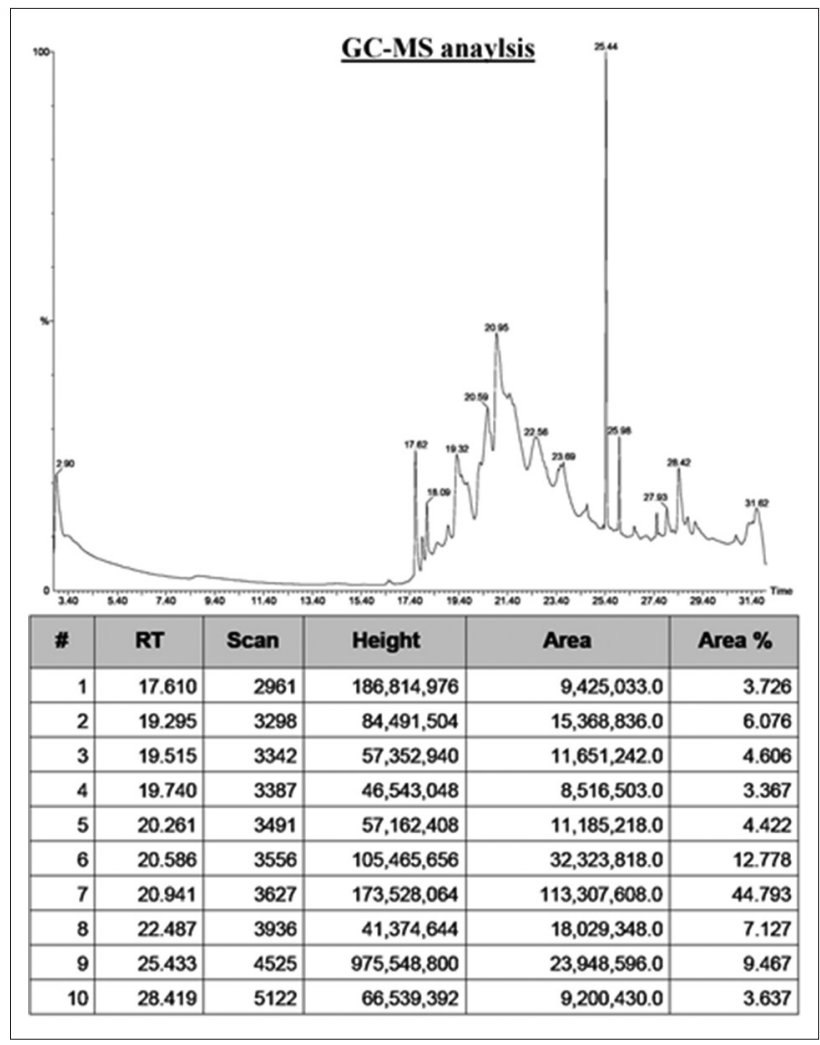

Fig. 2: Gas chromatography-mass spectrometry analysis of the ethanol extract of Terminalia catappa leaves, with area $\%$ analysis of pharmaceutical research [26-29]. India is a tropical country filled with a large amount of pharmaceutically valuable plants that demonstrate preferred bioactivity better than the available standard pure compound molecules. The fact that these plants consist of multiple bioactive molecules of similar and/or distantly related chemical molecules provides an aggregated and synergistic effect that supersedes the activity of single mode of action of pure chemically synthesized molecules [30-32]. The difficulty in purification and mass production of the phytochemical molecules is the greatest hurdle in developing marketable drugs from the plant sources. However, these phytochemicals have great potential to be developed into a marketable drug. The results of this current study strongly suggest that the phytochemicals of T. catappa leaves have significant antibacterial activity against Gram-positive SA and drug-resistant MRSA bacterial pathogens. Further analytical study and literature review identified the phytochemical molecules present in the T. catappa leaves. Such identified molecules were further subjected to protein-ligand docking study, to identify the possible mechanism of action for the observed antibacterial activity. The in silico studies suggest that the crude ethanol extract of T. catappa exhibits a synergistic effect by targeting multiple proteins such as topoisomerase IV, DHPS, and PBP2a protein, conferring both bactericidal and bacteriostatic effects on the bacterium. Further purification and identification of the individual phytochemicals would greatly benefit understanding the mechanism of action individually. Studies are currently being pursued in purification and analysis of pure phytochemicals from $T$. catappa leaves. The results of this study prove that T. catappa leaf extract demonstrates significant anti-MRSA activity, with potential for medicinal values.

\section{ACKNOWLEDGEMENT}

The authors thanks St.Josephs College (Autonomous), Bengaluru, for providing facilities to carry out this reasearch.

Table 1: List of identified phytochemicals present in leaves of T. catappa

\begin{tabular}{|c|c|c|}
\hline Phytochemical & $\begin{array}{l}\text { Molecular } \\
\text { weight }\end{array}$ & References \\
\hline Geraniin & $952.648 \mathrm{~g} / \mathrm{mol}$ & Griffiths LA. On the distribution of gentisic acid in green plants. J Exp Biol 1959;10:437. \\
\hline Gentisic acid & $194.118 \mathrm{~g} / \mathrm{mol}$ & \\
\hline Kaempferol & $286.239 \mathrm{~g} / \mathrm{mol}$ & List PH, Horhammer L. Hager's Handbuch der Pharmazeutischen Praxis. Vol. 2-6. Berlin: Springer-Verlag; \\
\hline Quercetin & $302.238 \mathrm{~g} / \mathrm{mol}$ & $1969-1979$. \\
\hline Chebulagic acid & $954.664 \mathrm{~g} / \mathrm{mol}$ & Tanaka T, Nonaka GI, Nishioka I. Tannins and related compounds. XLII. Isolation and characterization of \\
\hline Corilagin & $634.455 \mathrm{~g} / \mathrm{mol}$ & four new hydrolyzable tannins, terflavins A and B, tergallagin and tercatain from the leaves of T. catappa \\
\hline Punicalagin & $1084.722 \mathrm{~g} / \mathrm{mol}$ & \\
\hline Punicalin & $782.528 \mathrm{~g} / \mathrm{mol}$ & \\
\hline Tercatain & $786.56 \mathrm{~g} / \mathrm{mol}$ & \\
\hline Terflavin A & $1086.738 \mathrm{~g} / \mathrm{mol}$ & \\
\hline Terflavin B & $784.544 \mathrm{~g} / \mathrm{mol}$ & \\
\hline
\end{tabular}

T. catappa: Terminalia catappa

Table 2: Binding energies of ligands present in Terminalia catappa against bacterial drug targets

\begin{tabular}{|c|c|c|c|c|c|}
\hline \multirow[t]{2}{*}{ Phytochemical } & \multirow[t]{2}{*}{ PubChem ID } & Topoisomerase IV & DHFR & DHPS & PBP2a \\
\hline & & \multicolumn{4}{|c|}{ Binding energy (kcal/mol) } \\
\hline Corilagin & 5578 & -5.8 & -7.2 & -5.8 & -5.3 \\
\hline Mupirocin & 250397 & -9.3 & -7.4 & -10.2 & -8.9 \\
\hline Quercetin & 3001497 & -8.6 & -7.3 & -9.2 & -7.2 \\
\hline Kaempferol & 5280343 & -7.7 & -8.7 & -7.7 & -7.8 \\
\hline Tercatain & 5280863 & -7.1 & -8.4 & -7.3 & -7.7 \\
\hline Terflavin B & 14411426 & -9.1 & -8.6 & -9.3 & -9.1 \\
\hline Gentisic acid & 14886031 & -8.9 & -8.9 & -9.5 & -8.3 \\
\hline Punicalagin & 44584733 & -10.1 & -8.4 & -9.3 & -9.1 \\
\hline Punicalin & 92131301 & -10 & -8.3 & -9.6 & -10.7 \\
\hline Terflavin A & 101589226 & -11.2 & -8.7 & -9.8 & -10.4 \\
\hline Granatin A & 131752596 & -11.3 & -7.8 & -9.5 & -9.4 \\
\hline
\end{tabular}

DHFR: Dihydrofolate reductase, DHPS: Dihydopteroate synthase, PBP2a: Penicillin-binding protein 2a 


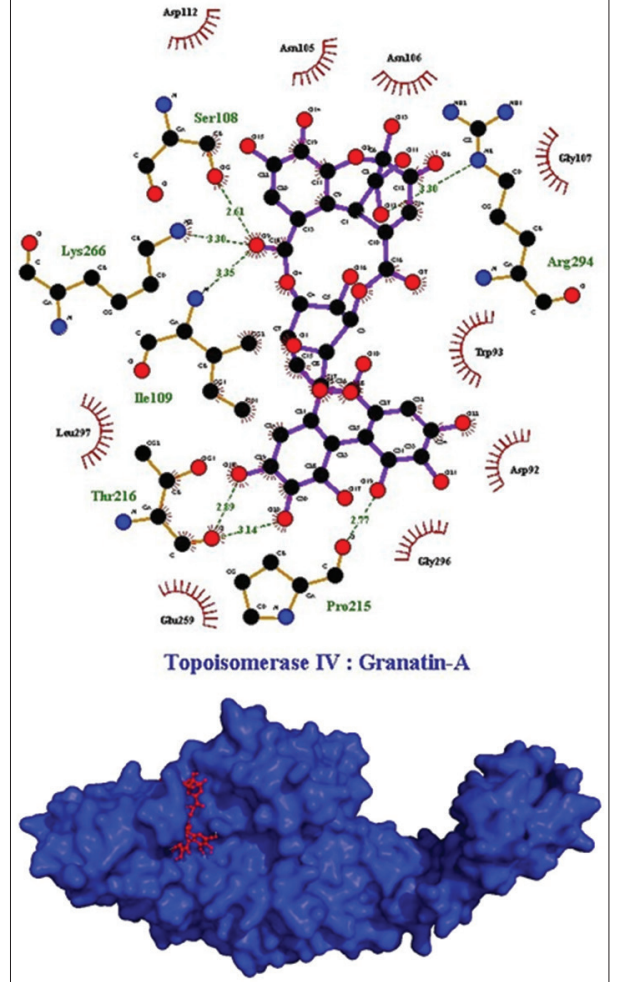

Fig. 3: Interaction between topoisomerase IV and granatin A

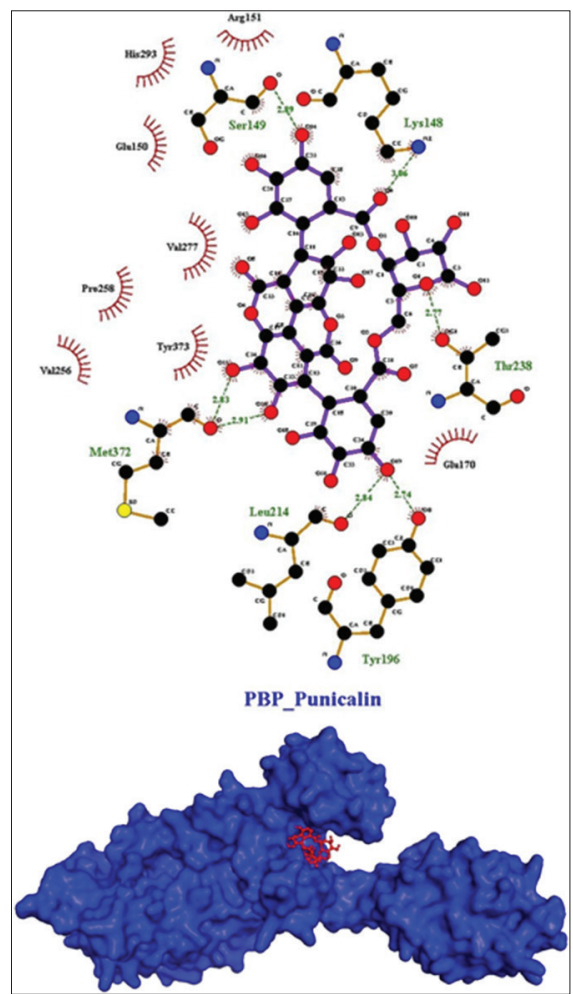

Fig. 4: Interactions between penicillin-binding protein 2a and punicalin

\section{AUTHOR CONTRIBUTIONS}

All authors provided equal contribution in research and manuscript preparation.

\section{CONFLICT OF INTEREST}

The authors confirm that there is no conflict of interest for this research work.

\section{REFERENCES}

1. Tapsell LC, Hemphill I, Cobiac L, Patch CS, Sullivan DR, Fenech M, et al. Health benefits of herbs and spices: The past, the present, the future. Med J Aust 2006;185:S4-24.

2. Tona L, Kambu K, Ngimbi N, Cimanga K, Vlietinck AJ. Antiamoebic and phytochemical screening of some congolese medicinal plants. J Ethnopharmacol 1998;61:57-65.

3. Neelavathi P, Venkatalakshmi P, Brindha P. Antibacterial activities of aqueous and ethanolic extracts of Terminalia catappa leaves and bark against some pathogenic bacteria. Int J Pharm Pharm Sci 2013;5:114-20.

4. Safford WE. The useful plants of the Island of Guam. Contributions from the United States National Herbarium; 1905. p. 9.

5. Masuda T, Yonemori S, Oyama Y, Takeda Y, Tanaka T, Andoh T, et al. Evaluation of the antioxidant activity of environmental plants: Activity of the leaf extracts from seashore plants. J Agric Food Chem 1999;47:1749-54.

6. Chen PS, Li JH, Liu TY, Lin TC. Folk medicine Terminalia catappa and its major tannin component, punicalagin, are effective against bleomycin-induced genotoxicity in Chinese hamster ovary cells. Cancer Lett 2000;152:115-22.

7. Tan GT, Pezzuto JM, Kinghorn AD, Hughes SH. Evaluation of natural products as inhibitors of human immunodeficiency virus Type 1 (HIV-1) reverse transcriptase. J Nat Prod 1991;54:143-54.

8. Lin CC, Hsu YF, Lin TC. Effects of punicalagin and punicalin on carrageenan-induced inflammation in rats. Am J Chin Med 1999;27:371-6.

9. Ratnasooriya WD, Dharmasiri MG. Effects of Terminalia catappa seeds on sexual behaviour and fertility of male rats. Asian J Androl 2000;2:213-9

10. Lin CC, Chen YL, Lin JM, Ujiie T. Evaluation of the antioxidant and hepatoprotective activity of Terminalia catappa. Am J Chin Med 1997;25:153-61.

11. Liu TY, Ho LK, Tsai YC, Chiang SH, Chao TW, Li JH, et al. Modification of mitomycin C-induced clastogenicity by Terminalia catappa L. in vitro and in vivo. Cancer Lett 1996;105:113-8.

12. Gunasena HP. Kottamba: Terminalia Catappa. Nairobi: World Agrofor; 2007.

13. World Health Organization. Medicinal Plants in the South Pacific. World Health Organization Regional Publications. Manilla: World Health Organization; 1998. p. 92.

14. Prazeres ES. Terminalia catappa preparations for the treatment of bronchial asthma. J Braz Pedido 1995;94:473-3.

15. Hecht SM, Berry DE, MacKenzie LJ, Busby RW, Nasuti CA. A strategy for identifying novel, mechanistically unique inhibitors of topoisomerase I. J Nat Prod 1992;55:401-13.

16. Kashiwada Y, Nonaka G, Nishioka I, Lee KJ, Bori I, Fukushima Y, et al. Tannins as potent inhibitors of DNA topoisomerase II in vitro. J Pharm Sci 1993;82:487-92.

17. Dorsch W, Wagner H. New antiasthmatic drugs from traditional medicine? Int Arch Allergy Appl Immunol 1991;94:262-5.

18. Tayel AA, Shaban SM, Moussa SH, Elguindy NM, Diab AM, Mazrou KE, et al. Bioactivity and application of plant seeds extracts to fight resistant strains of Staphylococcus aureus. Ann Agric Sci 2018;63:47-53.

19. Ravi L, Manasvi V, Lakshmi PB. Antibacterial and antioxidant activity of saponin from Abutilon indicum leaves. Asian J Pharm Clin Res 2016;9:344-7.

20. Sundar RD, Segaran G, Shankar S, Settu S, Ravi L. Bioactivity of Phoenix dactylifera seed and its phytochemical analysis. Int J Green Pharm 2017;11:6.

21. Sharma D, Rani R, Chaturvedi M, Yadav JP. Antibacterial capacity and identification of bioactive compounds by gems of Allium cepa. Int J Pharm Pharm Sci 2018; 10:116-21.

22. Krishna S, Chandrasekaran S, Dhanasekar D, Perumal A. GCMS analysis, antioxidant and antibacterial activities of ethanol extract of Anisomeles malabarica (L.) R.Br. ex. Sims leaves. Asian J Pharm Pharmacol 2019;5:180-7.

23. Abirami M, Kannabiran K. Antibiotic potency of extract from Streptomyces isolated from terrestrial soil of Amirthi forest, India. Walailak J Sci Technol 2017;14:711-21.

24. Derwich E, Benziane Z, Chabir R, Taouil R. In vitro antibacterial 
activity and gc/ms analysis of the essential oil extract of leaves of Rosmarinus officinalis grown in morocco. Int $\mathrm{J}$ Pharm Pharm Sci 2011;3:89-95.

25. Pisal P, Deodhar M, Kale A, Nigade GB, Pawar S. Design, synthesis, docking studies and biological evaluation of 2-phenyl-3-(substituted benzo[d] thiazol-2-ylamino)-quinazoline-4(3h)-one derivatives as antimicrobial agents. Int J Pharm Pharm Sci 2018;10:57-61.

26. Vinaygopal J, Krishnan K. Interaction of 2, 5-di-tert-butyl-1, 4-benzoquinone with selected antibacterial drug target enzymes by in silico molecular docking studies. Am J Drug Discov Dev 2013;3:200-5.

27. Leelakrishnan S, Palaniswamy C. Exploring the ability of Streptomyces antibiotics to combat methicillin resistant Staphylococcus aureus using in silico studies. Adv Appl Sci Res 2012;3:3502-13.

28. Ravi L, Krishnan K. Benzoyloxy-ethyl-carbamic acid: A novel anticancerous secondary metabolite produced by Streptomyces globosus VITLGK011. Indian J Exp Biol 2017;55:411-20.

29. Ravi L, Ragunathan A. Potential drug targets for Aloin and microdontin: An in-silico analysis. Asian J Pharm Clin Res 2016;9:194-6.

30. Pezzani R, Salehi B, Vitalini S, Iriti M, Zuñiga FA, Sharifi-Rad J, et al. Synergistic effects of plant derivatives and conventional chemotherapeutic agents: An update on the cancer perspective. Medicina (Kaunas) 2019;55:e110.

31. Sibanda $\mathrm{T}, \mathrm{Okoh} \mathrm{A}$. The challenges of overcoming antibiotic resistance: Plant extracts as potential sources of antimicrobial and resistance modifying agents. Afr J Biotechnol 2007;6:25.

32. Yuan H, Ma Q, Cui H, Liu G, Zhao X, Li W, et al. How can synergism of traditional medicines benefit from network pharmacology? Molecules 2017;22:e1135. 